\title{
Article \\ Passive Solar Solutions for Buildings: Criteria and Guidelines for a Synergistic Design
}

\author{
Giacomo Cillari * (D), Fabio Fantozzi (D) and Alessandro Franco \\ Department of Energy, Systems, Territory and Constructions Engineering, University of Pisa, \\ Largo Lucio Lazzarino, 56126 Pisa, Italy; f.fantozzi@ing.unipi.it (F.F.); alessandro.franco@ing.unipi.it (A.F.) \\ * Correspondence: giacomo.cillari@phd.unipi.it
}

Featured Application: Optimization of passive solar strategies to minimize building energy demand.

check for

updates

Citation: Cillari, G.; Fantozzi, F.;

Franco, A. Passive Solar Solutions for Buildings: Criteria and Guidelines for a Synergistic Design. Appl. Sci. 2021, 11,376. https://doi.org/10.3390/ app11010376

Received: 14 November 2020 Accepted: 29 December 2020 Published: 2 January 2021

Publisher's Note: MDPI stays neutral with regard to jurisdictional clai$\mathrm{ms}$ in published maps and institutional affiliations.

Copyright: (C) 2021 by the authors. Licensee MDPI, Basel, Switzerland. This article is an open access article distributed under the terms and conditions of the Creative Commons Attribution (CC BY) license (https:// creativecommons.org/licenses/by/ $4.0 /)$.

\begin{abstract}
Passive solar system design is an essential asset in a zero-energy building perspective to reduce heating, cooling, lighting, and ventilation loads. The integration of passive systems in building leads to a reduction of plant operation with considerable environmental benefits. The design can be related to intrinsic and extrinsic factors that influence the final performance in a synergistic way. The aim of this paper is to provide a comprehensive view of the elements that influence passive solar systems by means of an analysis of the theoretical background and the synergistic design of various solutions available. The paper quantifies the potential impact of influencing factors on the final performance and then investigates a case study of an existing public building, analyzing the effects of the integration of different passive systems through energy simulations. General investigation has highlighted that latitude and orientation impact energy saving on average by 3-13 and 6-11 percentage points, respectively. The case study showed that almost $20 \%$ of the building energy demand can be saved by means of passive solar systems. A higher contribution is given by mixing direct and indirect solutions, as half of the heating and around 25\% of the cooling energy demand can be cut off.
\end{abstract}

Keywords: solar energy; building energy performance; energy saving; passive solar design; synergistic design

\section{Introduction}

Energy use in the residential sector represents a great share of the global energy demand, attested between $20 \%$ and $40 \%$ of the total [1]. Each country has developed specific energy efficiency strategies for the civil sector. Firstly, the main attention concerned energy conservation, focusing on the building envelope insulation that can reduce energy demand by up to $28 \%$ [2]. Then the focus moved to increasing the efficiency of Heating Ventilation and Air Conditioning system (HVAC) systems, that are the main building energy consumption source and commonly do not operate efficiently [3]. In a nearly zero-energy building (nZEB) perspective, the integration of different strategies regarding envelope insulation, heat generation, shading, and control devices is fundamental to minimize building conditioning loads, so as to be able to maximize the share of energy demand covered by renewable energy sources. It must also be taken into account that residential space heating is responsible for $86 \%$ of building energy demand and can easily take advantage from renewable sources [4]. Among the various alternatives, solar energy represents the best option for buildings as one of the most accessible and easily exploitable, even if its current contribution to global energy supply is still imperceptible [5]: it can be directly exploited by heating up the building through solar irradiation, or indirectly by means of photovoltaic (PV) or solar thermal systems. As Table 1 data from International Energy Agency (IEA) [6] show, in a scenario where mandatory building energy codes 
will almost totally cover construction activity by 2030, with a nZEB share forecast of $50 \%$, the sales of heat pumps, which can be coupled with PV as a renewable production system, are slowly but constantly increasing, between 0.3 and $0.5 \%$ on a yearly basis, with fossil fuel-based equipment that, after a peak in 2014, is gradually decreasing. These data highlight the core role that solar energy plays in building design in the near future: by properly combining photovoltaic and solar thermal systems, indeed, solar energy can provide at least $76 \%$ of the primary energy demand of a residential building, with a short payback period [7].

Table 1. (a) Heating technology sales, (b) global building construction area by type of building code.

\begin{tabular}{|c|c|c|c|c|c|}
\hline $\begin{array}{l}\text { Heating } \\
\text { Technology }\end{array}$ & $\begin{array}{l}\text { Fossil fuel-Based } \\
\text { Equipment }\end{array}$ & $\begin{array}{l}\text { Conventional } \\
\text { Electric } \\
\text { Equipment }\end{array}$ & Heat Pumps & District Heat & $\begin{array}{l}\text { Other } \\
\text { Renewables and } \\
\text { Hydrogen-Based }\end{array}$ \\
\hline 2010 & $59.7 \%$ & $21.1 \%$ & $2.9 \%$ & $8.3 \%$ & $8 \%$ \\
\hline 2012 & $57.9 \%$ & $19.9 \%$ & $3.3 . \%$ & $10.1 \%$ & $8.8 \%$ \\
\hline 2014 & $60.1 \%$ & $18.5 \%$ & $3.4 \%$ & $10.2 \%$ & $7.8 \%$ \\
\hline 2016 & $57.9 \%$ & $21.2 \%$ & $3.9 \%$ & $9.1 \%$ & $7.9 \%$ \\
\hline 2018 & $57.1 \%$ & $20.6 \%$ & $4.3 \%$ & $9.4 \%$ & $8.6 \%$ \\
\hline \multicolumn{6}{|c|}{ (a) } \\
\hline Year & \multicolumn{2}{|c|}{$\begin{array}{l}\text { Constructions without building } \\
\text { energy code }\end{array}$} & \multicolumn{2}{|c|}{$\begin{array}{l}\text { Constructions with mandatory } \\
\text { building energy code }\end{array}$} & nZEBs \\
\hline 2019 & \multicolumn{2}{|c|}{5150} & \multicolumn{2}{|c|}{3750} & 250 \\
\hline 2025 & \multicolumn{2}{|c|}{3300} & \multicolumn{2}{|c|}{3100} & 3350 \\
\hline 2030 & \multicolumn{2}{|c|}{250} & \multicolumn{2}{|c|}{5000} & 5250 \\
\hline
\end{tabular}

(b)

Despite the main contribution in a modern building coming from active solar systems commonly integrated in a new building [8], passive solar strategies represent an energy reduction design feature with a high potential to dramatically reduce building energy demand [9] through energy promotion, buffering and prevention, influencing heating, cooling, ventilation loads, and building's system size. The main advantages of passive solutions include variety, versatility, simplicity, generally low initial and maintenance cost, and long lifetime [10] involving different building components, from walls to roofs. The effectiveness of passive solar solutions depends on a wide variety of design parameters [11]. Like all solar based devices, the performance is mainly related to the latitude, as it influences the average weather conditions and solar radiation on the collector surface. The maximum impact is expressed at medium latitudes, where cold winter temperature and long sunshine create the ideal conditions to exploit passive solutions. The benefit is also related to the interaction with the building and its users as heat delivery, shading, or ventilation must comply with the comfort requirements of the occupants: the magnitude of passive systems' gains becomes more relevant in highly energy consuming buildings like public or office ones.

The aim of the present paper is to provide a theoretical background of the parameters influencing the applicability and integrability of the various passive solar solutions in buildings and analyze how their synergy affects building energy performance. The scope of this analysis is to determine the impact of the different passive solutions while varying some controllable variables: the paper reports the first results of the investigation, where the most relevant influencing variables, such as latitude, orientation, building use, and shape factors, have been considered. Not much research has analyzed the topic from a general point of view in order to develop guidelines for passive solar application mainly providing a more qualitative outcome, describing the affecting parameters and defining rules of thumbs for sizing and related possible expected solar savings [12]. Other investigations focused on a specific topic, e.g., orientation, analyzing the effects by a deep theoretical 
background validated by measures and results from experimental activity [13]. The present paper follows a different approach as it intends to quantify the effects of passive solar strategies in terms of energy savings in different conditions: this will allow to determine the most suitable solutions in different cases and to define design guidelines according to the quantified impact of the variables analyzed.

The influencing parameters work together in defining the performance of a passive solar strategy: heating and cooling must be provided according to the living patterns that depend on building use, but also orientation that determines room distribution. Climate is linked to latitude and affects the energy balance and operativity by determining sun hours and lighting levels. Cost depends on the integrability in building design, thus, on the kind of structure and building shape: integration of massive systems in heavyweight buildings, for example, would be relatively easy, but could represent a high cost for lightweight ones. As all these elements work in synergy, a synergy of different strategies may achieve a better result in terms of energy saving. Recent investigations on passive solar systems and design integration in buildings have generally focused on spot solutions, either through a set of parametric simulation to verify and optimize the contribution of the asset to the building [14], or to characterize, evaluate, and maximize the performance of a specific device in individual applications [15]. The present paper intends to evaluate the efficacy of the synergy of different passive strategies and quantify the impact on building energy demand. Both direct, indirect, and isolated solutions can be designed to minimize each other's side effects. Direct systems that only provide heating, but faster than any other solution, are a perfect solution for a nonresidential building that needs to heat up quickly to reach indoor air comfort levels. On the other side, indirect systems can be exploited as solar chimneys to get ventilation and reduce discomfort due to overheating caused by wide glazed openings, or to provide cooling through roof ponds. In residential buildings, sunspaces can be used as a passive plenum of warmed air in winter, as a more manageable solution than high-inertia massive systems or direct systems with heat storage. By merging direct systems and sunspaces, more uniform heat delivery can be achieved, while a ventilated Trombe wall can be used in synergy with the sunspace to get higher indoor cross ventilation. A proper combination of direct, indirect, and shading systems can guarantee passive heating most of the winter season and minimize overheating in summer. Synergistic design must optimize the combination of different systems to minimize the need of HVAC contribution and promote the achievement of a zero-energy building. The paper analyzes the effect of synergistic, complementary strategies on a real office building, with different levels of intervention complexity, moving from simple, less expansive solutions, to composite and integrated ones, to quantify the reachable savings.

A brief description of the most common passive solutions is provided in Section 2, defining how extrinsic and intrinsic parameters work to determine the suitability of a specific passive system according to building kind. The influence of basic parameters affecting energy modelling of solar based devices is examined. Section 3 includes the methodology description and simulation settings of both the general investigation and the case study. Section 4 provides the results of the preliminary quantification of the impact of the different variables on building demand and then analyzes the outcomes of the case study of a public office building to evaluate the effect of possible combined passive strategies on a real building and determine the share of energy saving achievable through a synergistic design. Finally, after a brief discussion in Section 5 on the limit and contribution of the results achieved, the main conclusions are outlined, to show the potential of a structural, planned integration of passive solar systems in buildings in terms of energy demand reduction.

\section{Passive Solar Systems}

The action of a passive solar system for buildings can be summarized in a resistive and capacitive combined model, as the one described in Figure 1. According to this description, passive solar systems can be suitable both for increasing, during the summer period, or 
reducing, in the winter season, thermal resistance of direct solar radiation as well as to introduce appropriate capacitive systems able to store a part of solar radiation.
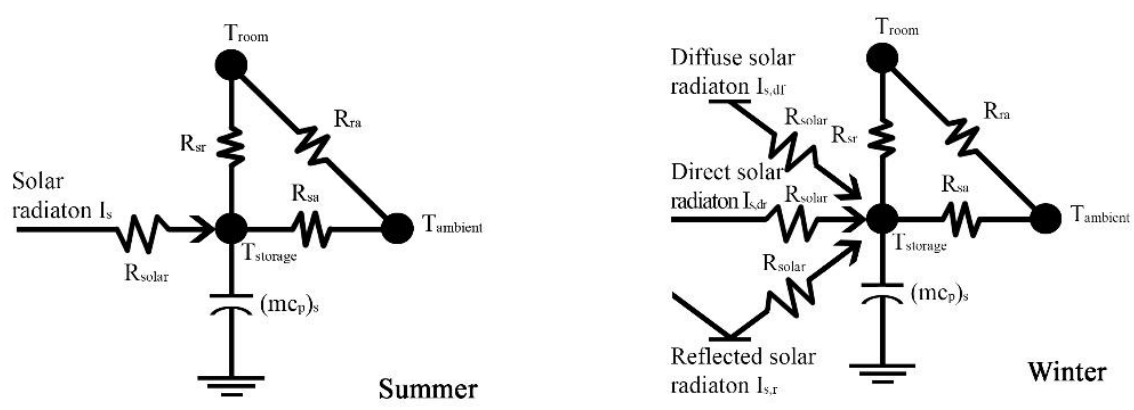

Figure 1. Conventional equivalent thermal circuit for passive solar heating building systems.

\subsection{An Overview of the Common Solutions}

Common categorization classifies passive solar systems into three classes. Direct gain systems collect solar energy through wide south-facing glazed envelopes: low construction cost, widely available and common technology represent the main advantages. No thermal storage is needed when these systems are sized to provide a small fraction of the heating load, but this could generate high indoor air temperature fluctuations. The most relevant disadvantage is related to glare discomfort or possible degradation from ultraviolet radiation [16]. The integration of insulation systems, thermal storage, external reflective surfaces, and shading systems (Figure 2) are the main possible improvements but can hugely impact the total cost. Indirect gain systems include a thermal mass placed between the solar collector and the indoor space that prevents indoor glare and ultraviolet degradation. A main disadvantage that can affect the system's lifespan is the maintenance, as proper access to the wall cavity for dust and condensation removal may be hard to achieve. In isolated gain systems, the collector and the storage are thermally isolated from the building: the main advantage is the independence of the system from the building.

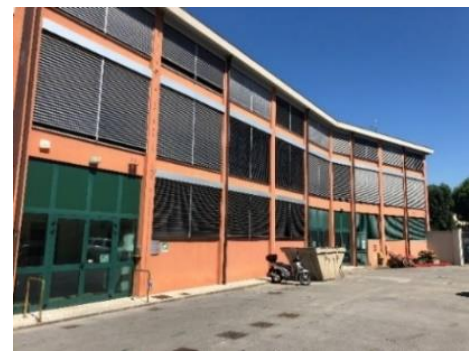

(a)

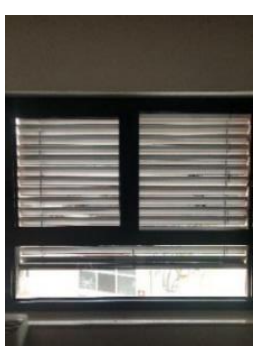

(b)

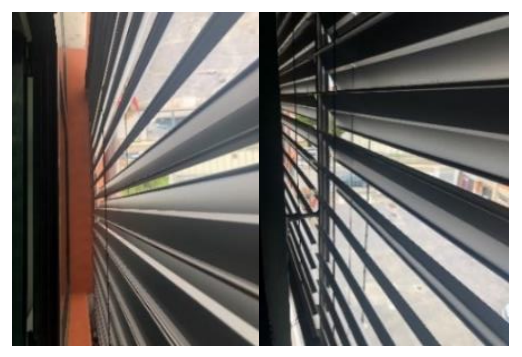

(c) (d)

Figure 2. Example of a passive solar system, external adjustable blinds applied in the case study building: (a) external view, (b) interior view, (c) louvres detail, (d) connection detail.

Integration of shading systems and reflective surfaces are simple strategies for both new and existing buildings with a low economic impact. At low latitudes, blinds on the east and west windows reduce heat gain by around $20 \%$ more than on the south-faced windows, whose contribution increases with latitude [17]. Investigation carried out by Alhuwayil et al. [18] shows that self-shading envelope in a multistory building has a lower payback period, 2 years, than additional insulation and low-e windows, with an energy consumption decrease of $20 \%$. In direct systems, $\mathrm{U}$ value and solar factors are the most relevant design parameters: for common glass, $U$ values around $1-1.5 \mathrm{~W} / \mathrm{m}^{2} \mathrm{~K}$ and a minimum solar factor of 0.3 is needed to have positive gain [19]. Low thermal resistance of the glass represents a critical weakness: use of triple glasses is a relevant energy saving 
measure in cold climates. Night insulation methods, such as roller-shade devices, are profitable but determine a not negligible extra cost.

In massive wall systems, the wall works as a storage mass buffering heat transfer. The greenhouse effect guaranteed by the external glazing improves the performance of the system. The thickness of the wall must be chosen according to the wall's material properties such as periodic and steady-state thermal transmittance, which define heat transfer rate, time lag, and decrement factor. Trombe wall adds convective heat exchange to the massive wall system by adding bottom and top openings to the wall: with the integration of outdoor vents, it can be used as a solar chimney [20]. This kind of configurations have good performance both in warm climates, cutting off $71.7 \%$ and $36.1 \%$ of heating and cooling demand, respectively, and in warm weather [14]. By exploiting fluid in the storage, water wall's heat transfer occurs by convection and the system is quite isothermal. This solution presents lower heat loss during night-time due to a lower surface temperature, and faster achievement of steady-state operating conditions, compared to other massive systems. Tests on a passive solar house with integrated water thermal storage walls showed an energy consumption reduction of $8.6 \%$ [21]. Roof pond systems, Figure 3, integrate water bags inside the roof structure: the large ceiling surfaces assure a more uniform heating distribution, but the effectiveness is limited to single-story buildings with an efficiency around $45 \%$, as less than half of the collected heat is transferred downward. The high structural loads and the low efficiency at medium-high latitudes due to the low horizontal irradiance represent the main disadvantages. Results from a field study of a roof pond report a reduction of the indoor temperature swing around 1/4th [22]. The Barra-Costantini system is based on the collector loop configuration, but the warmed air flows inside a cavity in the ceiling and is finally released at the non-sun-facing rooms: this system guarantees a diffuse heat distribution and storage suitable for multistory buildings and is exploitable for building ventilation. The main disadvantage is the hard maintenance due to dust or condensation in the cavity. In temperate climates, this configuration can reach an annual heating energy saving percentage from 60 to $70 \%$, but with a payback period of 25 years [23].

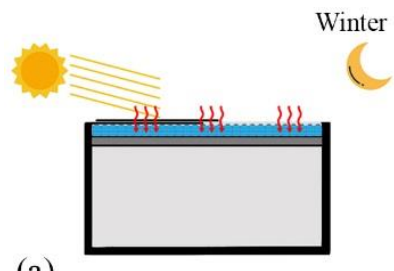

(a)
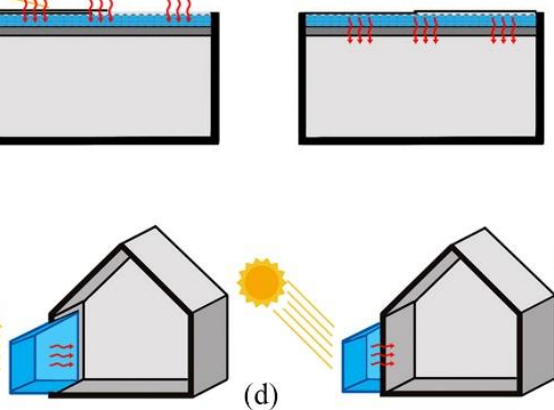

(d)

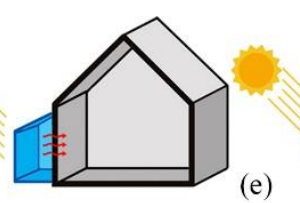

(e)

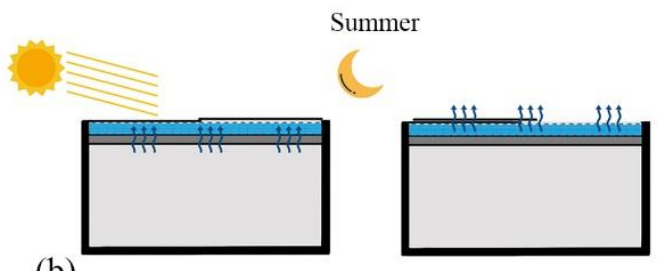

(b)

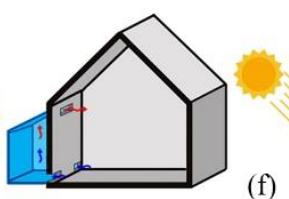

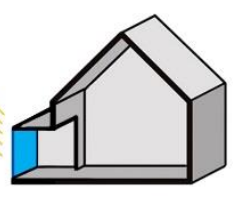

Figure 3. Water systems: (a) roof ponds winter mode (day and night), (b) roof ponds summer mode (day and night); sunspaces: (c) integrated, (d) attached, (e) attached ventilated, (f) sunporch.

Collector loops are based on convective heat exchange: these systems are perfectly suitable for lightweight insulated structures as easily integrable by adding an external glazing to the south façade. Convective loops also contribute to indoor ventilation. Likewise, thermosyphon systems consists of solar-glazed collectors with a black metal absorber. The most common application of these kinds of strategies in buildings is ventilated facades: in summer, the ventilated air gap and the reflective covering reduce the heat entering in the building, decreasing the cooling demand, while in cold weather conditions, the air gap reduces heat losses through the envelope, guaranteeing high air conditioning related 
savings. The system can also exploit the chimney effect to set up natural ventilation that helps in heat and moisture removal.

A sunspace layout is related to its use: as Figure 3 shows, integrated sunspaces act as large direct gain systems, while externally attached sunspaces work as indirect systems. A sunspace can be exploited to preheat external air [24], and works as a buffer zone. Although representing a possible additional living space is an advantage, the high construction cost and the compliance with local requirements limit sunspace implementation. The role of thermal storage is relevant: energy saving can be enhanced from $10-15 \%$ to $80 \%$ by adding a water-based storage system [15]. Achievable by installing windows or sheets in a south-facing balcony, sunporches represent a simple and cheaper solution for existing buildings, thus a valid energy retrofit strategy [25].

Building orientation and shape are basic passive strategies that highly affect both the base building energy load and the performance of other passive solutions by defining solar exposure. When designing a new building, difference in heating demand from a regular-squared to an irregular building can account for about $50 \%$, while proper site orientation can save up to $40 \%$ [26].

\subsection{Standard Modelling}

As clearly evidenced in the models of Figure 1, the sizing of a distinct passive solar system with a defined objective appears to be a quite difficult task due to the synergistic effects of different parameters that act together in defining the effectiveness of a passive solar system. Therefore, energy performance can only be determined by considering this synergy. As Table 2 shows, parameters can be classified into extrinsic factors, external to the passive system, such as latitude or building shape, and intrinsic, such as collector inclination and orientation. These factors have a different impact on final performance: they act directly on the incident solar radiation or influence the operativity of the passive system and its integrability in building design. All these parameters contribute to the performance of passive solar systems at different stages of a project: while building orientation, shape, and position should be adapted to maximize the potential performance of passive solar systems, building use and latitude are usually given parameters, so they must be considered for a preliminary screening to limit the choice to the most suitable strategies. Then, another set of parameters allows to identify the most appropriate system for a specific building. The selection process is strictly country-dependent, as microclimatic conditions, architectural details, and related costs widely differ from place to place.

Table 2. Influence of design parameters.

\begin{tabular}{|c|c|c|c|}
\hline Parameters & Kind & Affected Element & $\begin{array}{c}\text { Influence on } \\
\text { Design Process }\end{array}$ \\
\hline Orientation & Intrinsic & Solar radiation & \multirow{3}{*}{$\begin{array}{c}\text { Design adaptation to } \\
\text { maximize } \\
\text { performance }\end{array}$} \\
\hline Building shape & Extrinsic & Integrability & \\
\hline Building positioning & Extrinsic & Solar radiation & \\
\hline Latitude & Extrinsic & Solar radiation & \multirow{3}{*}{$\begin{array}{l}\text { Primary selection } \\
\text { parameters }\end{array}$} \\
\hline Building use & Extrinsic & Operativity & \\
\hline Surface area to volume ratio & Extrinsic & Integrability & \\
\hline $\mathrm{N}^{\circ}$ of services involved & Intrinsic & Operativity & \multirow{5}{*}{$\begin{array}{l}\text { Secondary selection } \\
\text { parameters }\end{array}$} \\
\hline Overheating sensitivity & Intrinsic & Operativity & \\
\hline Adaptability & Intrinsic & Integrability & \\
\hline Range of the effect & Intrinsic & Operativity & \\
\hline $\begin{array}{l}\text { Cost of construction and } \\
\text { maintenance }\end{array}$ & Intrinsic & Integrability & \\
\hline $\begin{array}{c}\text { Cost/performance ratio per } \\
\text { unit area }\end{array}$ & Intrinsic & Integrability & Sizing parameters \\
\hline
\end{tabular}


The performance of each solar system is related to incident solar irradiance $G\left(\mathrm{~W} / \mathrm{m}^{2}\right)$, that depends on the different position of the site, latitude and longitude, on the different seasons, on the hour of the day, and on the position of the surface exposed to solar radiation. Solar irradiance can be evaluated with the following law [27]:

$$
G_{T}=G_{o n} \times \tau \times \cos \theta
$$

with

$$
\begin{gathered}
G_{o n}=G_{s c}\left(1+0.033 \cos \left(\frac{360 n}{365}\right)\right) \\
\cos T=\sin \delta \sin \phi \cos \beta-\sin \delta \cos \phi \sin \beta \cos \gamma+\cos \delta \cos \phi \cos \beta \cos \omega+ \\
+\cos \delta \sin \phi \sin \beta \cos \gamma \cos \omega+\cos \delta \sin \beta \sin \gamma \sin \omega \\
\tau=e^{-b \lambda^{-\alpha} m a}
\end{gathered}
$$

where $G_{T}$ is global irradiance on a tilted surface, $G_{s c}$ is the solar constant, $\theta$ is angle between surface normal and incident radiation (Figure $4 \mathrm{a}$ ) and $\tau$ represents atmospheric attenuation of solar radiation. Figure $4 \mathrm{~b}$ reports the maximum daily solar irradiance per month at different latitudes.

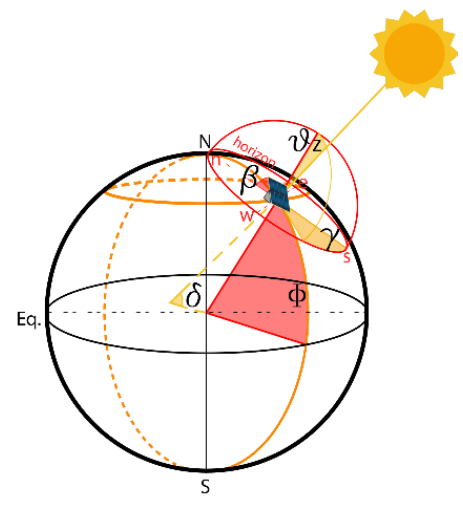

(a)

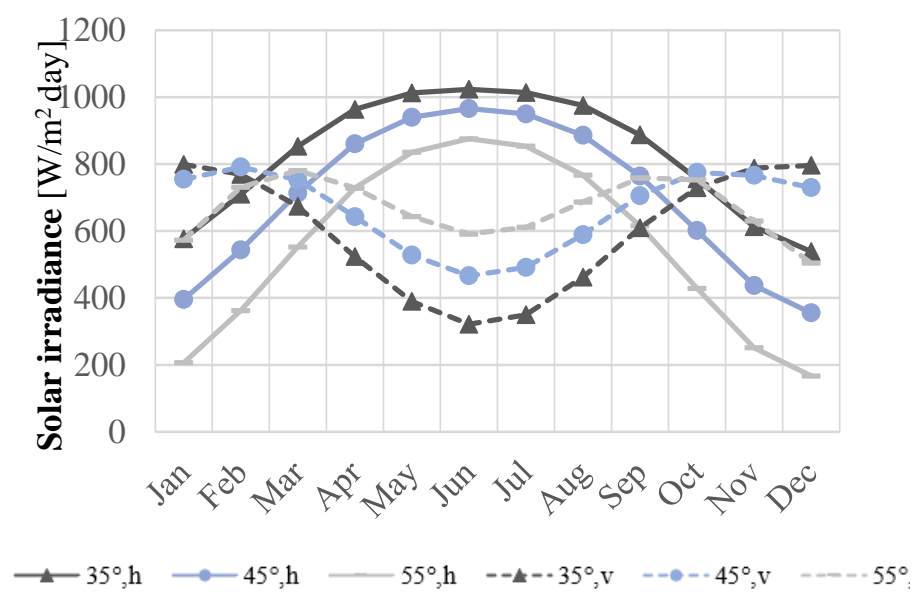

(b)

Figure 4. (a) Angles related to sun position; (b) maximum daily solar irradiance per month at different latitudes on a horizontal, h, and a vertical, v, surface.

As Equation (3) states, latitude and surface inclination are the most impactful parameters to determine solar irradiance on a surface. Latitude affects the number of hours of sunlight on the surface. The best performance can be achieved at medium latitudes: at low ones, high solar radiation guarantees a high amount of collectable energy, but the short heating season makes the integration less cost-effective with a higher risk of overheating; at high latitudes, energy saving can be higher, but the lower solar radiation and shorter daytime limit the operativity, with a need of insulation, due to the lower average temperatures, that increases the total cost.

\subsection{Synergy of Influencing Parameters}

A generic model for passive solar systems, like the one in Figure 1, is internally ruled by three main resistances related to heat exchange among room, ambient, and storage, and characterized by a capacitive massive element. It is also externally stressed by the incident solar radiation on the collector. In summer, shading systems represent the most relevant resistance, while in winter, all kinds of solar radiation contribute with specific resistances. In building applications, materials and structures work in synergy with the 
elements previously analyzed to define passive system operativity. Glass properties are the first element that intervene. Once the incident solar irradiance has been determined with Equation (1), the energy transferred inside the building can be evaluated with the following balance:

$$
H \times A=Q_{t}+Q_{r}+Q_{a, \text { out }}+Q_{a, \text { in }}
$$

where $H$ is global solar radiation on the window, $A$ is windows surface, while subscript $t$ represents the amount of energy transferred, $r$ - the reflected share, a,out - the energy absorbed and retransferred outside, whereas $a, i n$ - the energy absorbed and transferred inside the building. The solar factor $(g)$, the main parameter related to glass, can be defined as the percentage of solar energy incident on the glass that is transferred indoor, as showed in Equation (6).

$$
g=\frac{Q_{t}+Q_{a, i n}}{H \times A}
$$

The solar factor depends on the composition and properties of the glass: from single to low emission glasses, the solar factor is almost halved, due to highly reduced transmittance.

The type of building structure and envelope materials affect the system's integrability [11] and the opportunity of exploiting building elements for heat storage with no extra cost. Integrated heat storage reduces indoor temperature fluctuation and extends the performance of a passive system. Density, specific heat capacity, and thermal diffusivity influence the rate of heat storage and the useful thickness involved in the process: high density and mass guarantee high heat capacity, while the higher the thermal conductivity, thus the diffusivity, the more readily the storage system absorbs heat and the deeper the material thickness involved is. The minimum thermal storage surface recommended by Balcomb [28] is six times the solar collector glazing area. Passive solar design solutions can be grouped according to the integrability, as shown in Figure 5, based on the kind of structure, light or heavyweight, and the suitability to new or existing buildings.

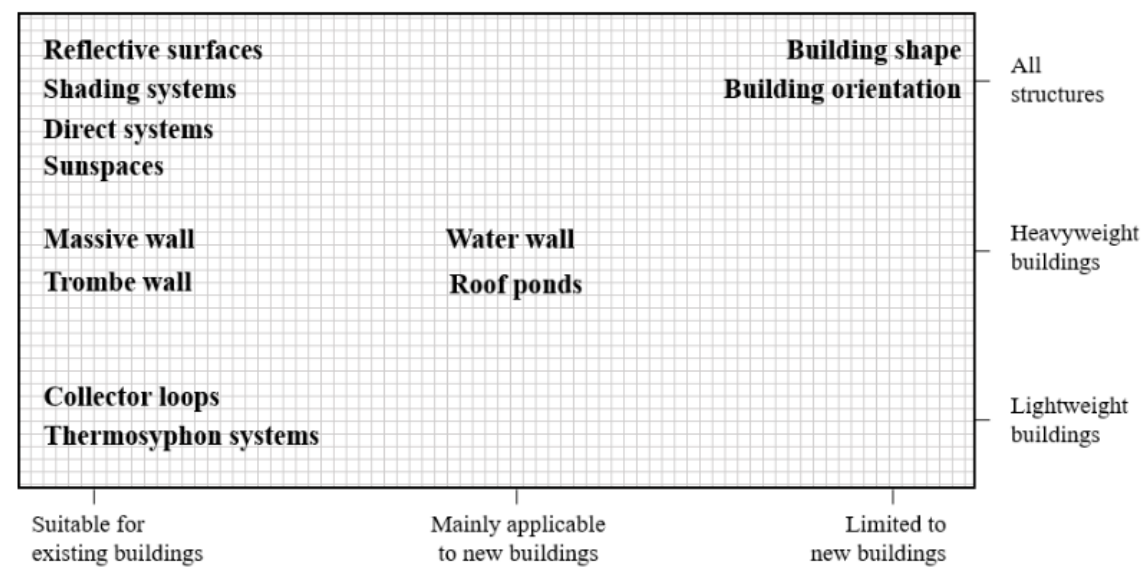

Figure 5. Classification of passive solar design strategies.

The building use and occupant's activity schedule are another set of parameters affecting the operation of a passive solar system: living pattern that varies according to the building use defines the period of comfort and that of possible setback. In office buildings, the main activity is focused on the middle of the day, from 7.00 a.m. to 5.00 p.m., while in residential buildings the time slot shifts to evening and morning. Educational buildings and offices, with a prevalent daytime use, are the most suitable for directly exploiting the heat provided by the sun. In residential buildings, the efficacy of passive solutions is related to heat storage effectiveness to deliver heat during night or cloudy days. 


\section{Performance Evaluation of Passive Solar Systems}

\subsection{General Investigation}

As the first investigation, a preliminary quantification of the impact of different parameters on the three classes of passive solar systems has been carried out through a set of simulations. The energy analysis has been carried out with the EnergyPlus ${ }^{\mathrm{TM}}$ simulation tool developed by US DoE. In order to properly compare the outputs, the simulations considered a standard application of different strategies: the same construction and structures have been used, with no specific optimization for different solutions. The simulations have been run during the winter period to evaluate the impact of the solar strategies on the building's heating demand. Two kinds of buildings, an office complex and an apartment building, have been analyzed with different surface to volume ratio, 0.4 and 0.6 , respectively, and different heating demand schedules: from 8.00 am to 7.00 pm on the weekdays and turned off in weekends for the office, while the opposite was set for the residential building. Another difference between residential and office building simulation occurred in schedule and magnitude of internal gains such as from equipment and appliances. Simulations have been set at Rome, $41^{\circ} 50^{\prime}$, and Frankfurt, $50^{\circ} 06^{\prime}$, to evaluate the incidence of latitude. The three strategies, a direct system, a ventilated Trombe wall, and a sunspace, have been simulated both with a north-south building axis and at $90^{\circ}$ rotation $(\mathrm{r})$, with east-west building axis. Both the models contained common building constructions with an external wall U-value of $0.40 \mathrm{~W} / \mathrm{m}^{2} \mathrm{~K}$. Base number and dimensions of the windows were set to comply with the minimum window-to-floor surface ratio of $1 / 8$ required by Italian legislation: fenestration constructions have a $U$ value of $1.76 \mathrm{~W} / \mathrm{m}^{2} \mathrm{~K}$ and $\mathrm{g}$ of 0.56 . With these settings and no passive systems installed, a benchmark value of energy demand of both office and residential buildings has been evaluated as a reference for energy saving of the passive solar strategies. The reference values for Rome and Frankfurt houses are 160 and $290 \mathrm{kWh} / \mathrm{m}^{2}$, respectively, while office building reference demand is $98 \mathrm{kWh} / \mathrm{m}^{2}$ in Rome and $112 \mathrm{kWh} / \mathrm{m}^{2}$ in Frankfurt.

Implementing the direct system, a wide glazed surface has been added on the southfaced wall or divided between the east and the west façade in the rotated case. Window extension was set at $15 \%$ of the floor, according to the common rule of thumb [29]: fenestration U-value and $g$ are $1.06 \mathrm{~W} / \mathrm{m}^{2} \mathrm{~K}$ and 0.6 , respectively, while a $10 \mathrm{~cm}$ concrete slab provides the ground floor construction with a heat storage mass. This simulation is the only one with a specific low emission window kind, as direct systems installed are part of the thermal zone and directly affect building energy balance. Regarding the indirect and isolated systems, they belong to a different thermal zone, which are not considered in building energy balance. In the indirect system simulation, the Trombe wall area accounted for $0.2 \mathrm{~m}^{2}$ per $\mathrm{m}^{2}$ of floor area, with an air cavity thickness of $15 \mathrm{~cm}$. The thickness of the external wall, $30 \mathrm{~cm}$, already provided a good buffering of the heat wave. In this simulation, the same clear glass construction of other windows has been applied to the glazed face of the Trombe wall. Finally, the sunspace modelled in the isolated system was designed as a sunporch linked to the main building through a patio door: its envelope was glazed with the ordinary kind of window, except for the floor, which had the same construction as the indoor floor.

\subsection{Analysis of a Case Study}

After a general investigation to quantify the impact of the different variables on the performance of the three kinds of passive solar strategies, another simulation was run to define possible effects of the synergy of different solutions on a case study of a real building. The aim was to provide a quantification of the energy saving that could be obtained with the design of passive solutions in an existing building. The selection of the case study has been influenced by various elements, as the positive effects of passive solar systems can be evaluated referring to both specific civil buildings for residential or public use. Between residential and public buildings, the latter result to be more energy consuming: daily use and commonly wide glazed envelopes make them also the most suitable kind of buildings 
for the implementation of passive solar systems. The European Directive 2010/31/UE [30], in fact, firstly focused its attention on public buildings, anticipating the requirement for nearly zero-energy buildings (nZEB) in new construction. For these reasons, the case study is based on the office building of the Department of Energy, Systems, Territory and Constructions Engineering of the University of Pisa, shown in Figure 6. The building hosts offices and research laboratories on two floors: the technical room for the building system at the ground level and the adjacent building with mechanical laboratories were not included in the simulation. It develops along the south-north axis, and is characterized by a wide glazed envelope, mainly equally east- and west-exposed with a gross window-to-wall ratio of $57.65 \%$.

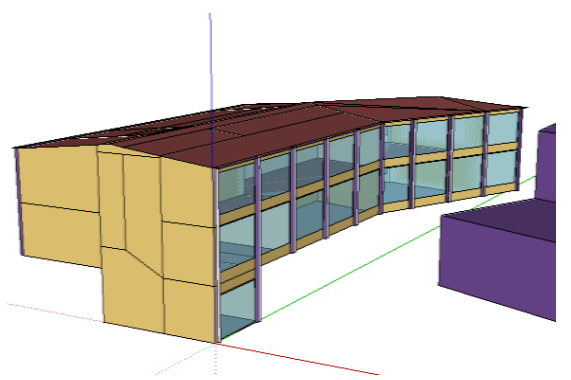

(a)

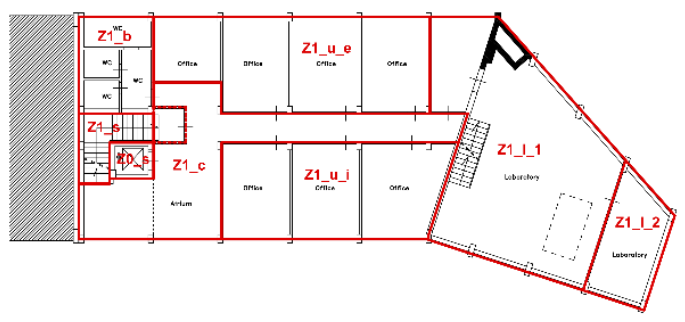

(b)

Figure 6. Case study building: (a) energy model; (b) standard floor plan

For energy modeling, people, lights, and equipment loads were considered; no mechanical system has been modelled, only natural ventilation to simulate the passive behavior of the building and its energy demand. Table 3 lists the main construction involved and internal gains used.

Table 3. Model details.

\begin{tabular}{cc}
\hline Construction & Thermal Conductivity $\left[\mathbf{W} / \mathbf{m}^{2} \mathbf{K}\right]$ \\
\hline External brick wall & 1.05 \\
External brickwork & 0.94 \\
External concrete wall & 2.50 \\
Office floor slab & 1.07 \\
Laboratories floor slab & 1.47 \\
Roof & 0.428 \\
\hline Load & Specific intensity $\left[\mathbf{W} / \mathbf{m}^{2}\right]$ \\
\hline Lights & 7.00 \\
Electric equipment & 5.00 \\
\hline
\end{tabular}

Zone ideal loads have been evaluated with a heating setpoint at $20^{\circ} \mathrm{C}$ and a cooling one at $26^{\circ} \mathrm{C}$. Natural ventilation through existing windows has been set according to the occupancy pattern and with an outdoor air temperature range between 15 and $30^{\circ} \mathrm{C}$.

The first solution investigated shading systems: given the high-glazed surface, this results as the easiest and most cost-efficient kind of passive solar solution. Fixed overhangs and external adjustable blinds, as the ones installed, were both simulated to compare their efficacy. The simulation has been set to activate the blind closing when 500 lux have been reached over the working plan or indoor air temperature rises above $25^{\circ} \mathrm{C}$, with a tilt angle configured to block direct beam solar radiation. A second passive strategy to reduce heat losses through the glazed envelope, focused on the integration of solar-control low-emissivity glasses. The windows chosen for this simulation had a solar control glass layer replacing common $4 \mathrm{~mm}$ clear glass, with a solar transmittance at normal incidence of 0.166 : window $\mathrm{U}$ value moved from 2.7 to $1.65 \mathrm{~W} / \mathrm{m}^{2} \mathrm{~K}$ while the solar heat gain coefficient 
decreased from 0.764 to 0.617 . To fully exploit the potential of passive solar strategies, different solutions must be combined and balanced to take advantage of the energy savings coming from each system, as they can act on distinct services and in distinct times: for this reason, a combined solution, with external blinds and low-e glasses, has also been investigated. With reference to the models in Figure 1, the strategies that are discussed with this simulation focus on intercepting the incident solar radiation by acting on solar resistance. In terms of equivalent circuit, shading and glass element defined a rheostat with a variable resistance, as shown in Figure 7: both the integration of fixed overhangs and adjustable blinds or solar control glasses determined variable heat gain for the building.

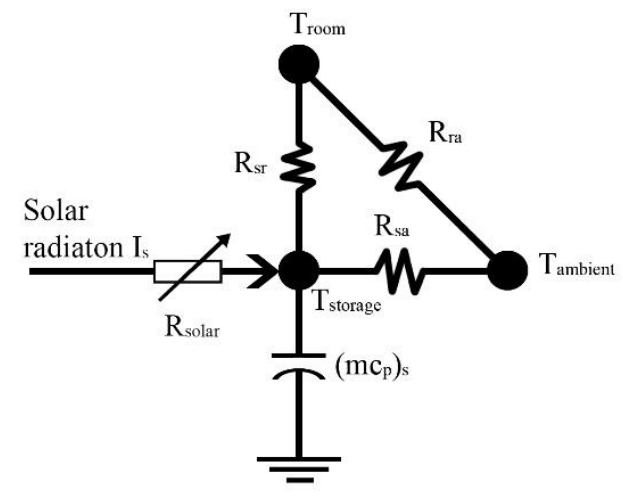

Figure 7. Conventional equivalent thermal circuit for passive strategies related to solar radiation resistance.

To get a deeper understanding of the combined effect of different solutions on the possible energy savings, a single module of the office building has been modelled, both in the basic case, in the combined case with a shading system activated, and in a Trombe wall configuration. In this last case, as shown in Figure 8, part of the external window has been replaced with the specified indirect system: while the direct gain system provides heating and lighting during the day, Trombe wall guarantees higher temperatures at night, leading to a lower demand in the morning when the HVAC system turns on. Moreover, the reduction of the glazed surface hugely reduces heat losses in winter or the unwanted heat gain in summer. The system has been modeled both as an unventilated Trombe wall with a full conductive heat exchange, and as a naturally ventilated one. Due to the high window-to-wall ratio, $50 \%$ substitution rate has been chosen, as it does not highly impact the needed lighting level on the working plan.

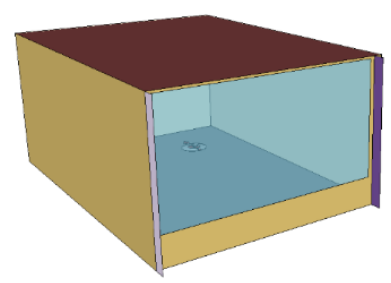

(a)

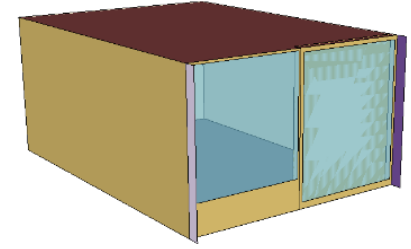

(b)

Figure 8. Single office module: (a) standard configuration; (b) Trombe wall configuration.

\section{Results}

Results of the general investigation on the impact of variables over passive systems performance have been analyzed both in terms of absolute values and by comparing the percentages of energy saving achievable. Figure 9 shows the results of the simulation: in terms of energy demand, the difference between the two latitudes, as shown in Figure $9 a, b$, increased as the surface-to-volume ratio increases, moving from the office to the residential buildings. For the office building, direct systems proved to be the most profitable solution 
in terms of energy saving for both locations, as the highest savings, $28.2 \%$ and $38.5 \%$ for Rome and Frankfurt, respectively, occurred in the rotated direct system configuration, as described by Figure 9c. For the apartment building, Figure 9d, the Trombe wall rotated setting reached the highest saving in Frankfurt, 12.8\%, and Rome, 22.3\%. A very different trend can be defined for office and residential buildings in terms of passive system performance. Data collected confirmed that daily use office buildings prefer direct systems, as indirect and isolated systems showed much lower values. The trend highlighted an increase of the savings moving from Rome to Frankfurt, due to the higher demand of the Frankfurt facility that can better exploit solar radiation during its colder season, except for the sunspace simulation, and an increment from standard to rotated configuration certified the higher efficiency of south-faced passive solar systems. Quite the opposite trend can be detected in residential buildings, as the energy savings decreased from Rome to Frankfurt, and the variation among direct, indirect, and isolated systems percentages was lower. As in the previous analysis, however, the rotated configuration showed higher results for both locations, establishing again the higher performance of south-faced systems.

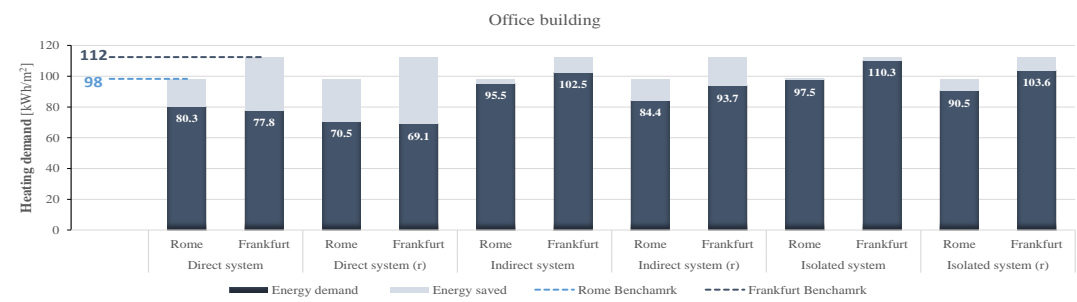

(a)

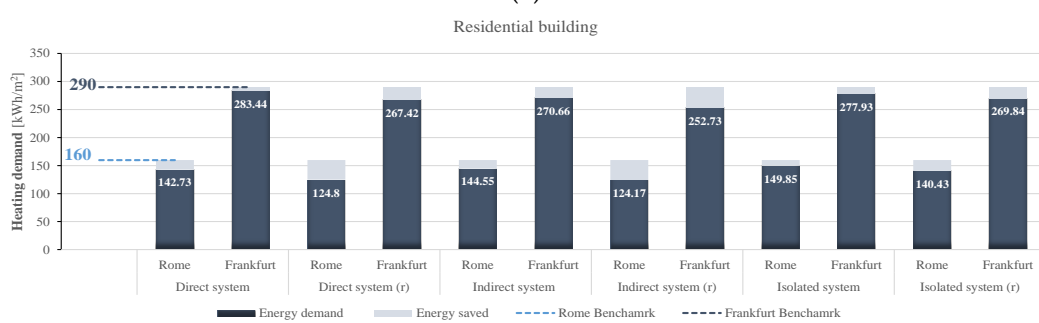

(b)

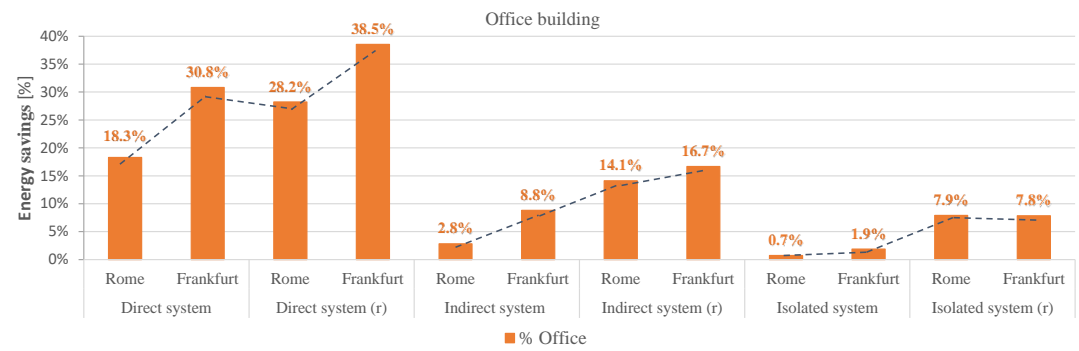

(c)

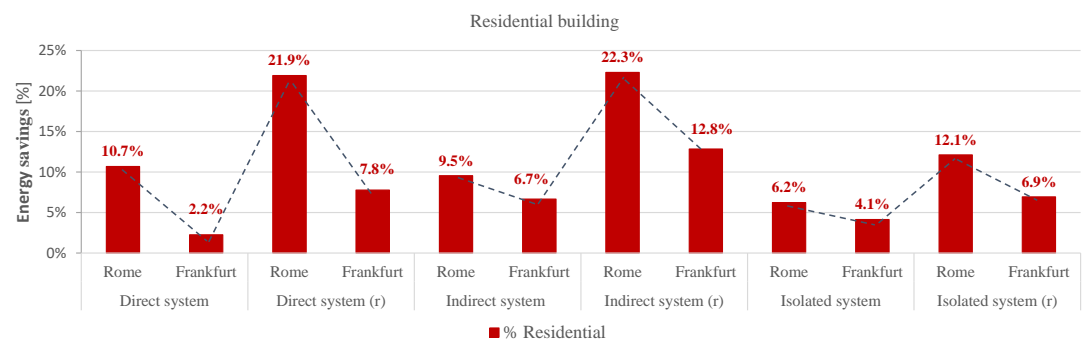

(d)

Figure 9. Heating energy demand in winter season: (a) office building; (b) apartment building; (c) percentage of energy saving in office building; (d) percentage of energy saving in residential building. 
Even building destination and use affect the performance of passive solar systems. While at Rome latitudes the difference between the two kinds of buildings was quite constant, as it went to $7.6 \%$ in standard and $6.3 \%$ in rotated direct systems to $6.7 \%$ and $8.2 \%$ in indirect and $5.5 \%$ and $4.2 \%$ in isolated ones, it greatly varied for Frankfurt: direct systems efficacy changed around $28.6 \%$ in standard and $30.7 \%$ in rotated configuration due to the low performance in residential application, while the range of indirect and isolated systems was between $1-4 \%$. Frankfurt values for residential buildings were generally lower than office ones, excluding the standard sunspace, while at Rome latitudes, except for the direct systems, residential values were higher than that of the office.

Latitude impact differs according to building destination: the office in Frankfurt showed higher energy saving potential than the Rome one, while the opposite occurred in the residential building analysis, where Rome percentages were higher than Frankfurt ones. The range of variation between the two latitudes was wider for direct systems, $12.5 \%$ and $10.3 \%$ in office or $8.5 \%$ and $14.1 \%$ in residential building, than in indirect and isolated solutions: for the north-south axis building, the gap was higher in the office application, around 12.5 percentage points in the direct system, 6 in indirect, and 1.2 in isolated, versus $8.5 \%, 2.8 \%$, and $2.1 \%$ for residential building direct, indirect, and isolated solutions, respectively. In the rotated configuration, the opposite occurred, since the gap between Rome and Frankfurt in residential application was higher than the corresponding value for office buildings.

Looking at the orientation impact, south-facing systems showed the highest values, but they must deal with summer overheating risk. The sensibility decreases as the latitude increases, with Rome gaps between standard and rotated configurations higher than Frankfurt ones. The influence of different building axis depends on building use: for Frankfurt latitude, the impact of orientation moved from $7.7 \%$ of energy saving variation in direct systems, $7.9 \%$ in indirect, and $5.9 \%$ in isolated ones in the office study to lower values in the residential analysis, $5.6 \%, 6.1 \%$, and $2.8 \%$ respectively. In Rome, the effect of orientation in residential application was higher than in office buildings, moving from $11.2 \%$ to $9.9 \%$ in direct systems and from $12.8 \%$ to $11.3 \%$ in indirect systems. Isolated sunspace solution represents an exception, as the residential gap of performance between standard and rotated configurations, $7.2 \%$, was higher than the office one, $5.9 \%$.

The lower residential building performance and the consequent lower sensitivity to orientation and latitude was attributable to the lack of optimization for the heat storage system. Analysing the results from the perspective of the systems, direct solutions showed the highest efficiency in reducing building energy demand, but they had higher sensitivity to orientation, 6 to 10 percentage points of variation, and latitude, 9-13\%, than indirect or isolated solutions.

Moving to the case study of the office building, four different strategies have been studied and results are shown in Table 4 . As a reference, the basic case, with no shading systems, determined an energy demand per total building area of $115.52 \mathrm{kWh} / \mathrm{m}^{2}$, with an almost equal energy consumption for heating and cooling purposes, $47.59 \mathrm{kWh} / \mathrm{m}^{2}$ and $45.66 \mathrm{kWh} / \mathrm{m}^{2}$, respectively. Due to the east and west exposure, the effectiveness of fixed overhangs was negligible, while the impact of external blinds to reduce the summer undesired heat gain while guaranteeing proper lighting levels for office work was relevant. The results show that while fixed shadings led to a very low energy demand variation, with only $1.28 \%$ energy saving in cooling, blinds cut off one third of the cooling energy demand, with an impact of $12.58 \%$ on total energy consumption. This result highlights the hidden potential of passive solar solutions that can provide a reduction in embodied and operational energy requirements over a life cycle [31]. As shown in Figure 10, indoor air temperatures in the office zone in free running conditions rise compared to the basic case due to the higher thermal resistance of the windows: results show a reduction around 15\% in heating demand, but the lower heat losses during the night generated a higher demand of energy in the cooling season. The analyzed synergy effect of the combined strategies individually, external blinds and low-e glasses, reduced by around a quarter the energy 
demand of the building, with a share for heating and cooling close to the highest values previously detected, $14.91 \%$ and $32.74 \%$, respectively.

Table 4. Energy demand for run simulations.

\begin{tabular}{|c|c|c|c|c|c|c|c|c|c|c|}
\hline \multicolumn{2}{|c|}{$\begin{array}{c}\text { Energy } \\
\text { Demand }\end{array}$} & \multirow{2}{*}{ 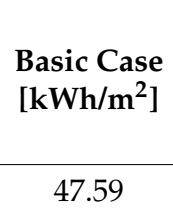 } & \multirow{2}{*}{$\begin{array}{c}\begin{array}{c}\text { Fixed } \\
\text { Over- } \\
\text { hang } \\
{\left[\mathbf{k W h} / \mathbf{m}^{2}\right]}\end{array} \\
47.81\end{array}$} & {$[\%]$} & \multirow{2}{*}{$\begin{array}{c}\begin{array}{c}\text { Adjustable } \\
\text { Blinds } \\
{\left[\mathbf{k W h} / \mathbf{m}^{2}\right]}\end{array} \\
48.20\end{array}$} & {$[\%]$} & $\begin{array}{c}\text { Solar } \\
\text { Control } \\
\text { Glass } \\
{\left[\mathbf{k W h} / \mathbf{m}^{2}\right]}\end{array}$ & {$[\%]$} & $\begin{array}{l}\text { Combined } \\
{\left[\mathrm{kWh} / \mathrm{m}^{2}\right]}\end{array}$ & {$[\%]$} \\
\hline & Heating & & & 0.46 & & 1.29 & 39.75 & -16.47 & 43.39 & -14.91 \\
\hline HVAC & Cooling & 45.66 & 45.07 & -1.28 & 30.51 & -33.17 & 46.26 & 1.32 & 33.05 & -32.74 \\
\hline \multicolumn{2}{|c|}{$\begin{array}{c}\text { Energy Per Total } \\
\text { Building Area }\end{array}$} & 115.52 & 115.16 & -0.32 & 100.99 & -12.58 & 108.28 & -6.27 & 93.48 & -19.08 \\
\hline
\end{tabular}

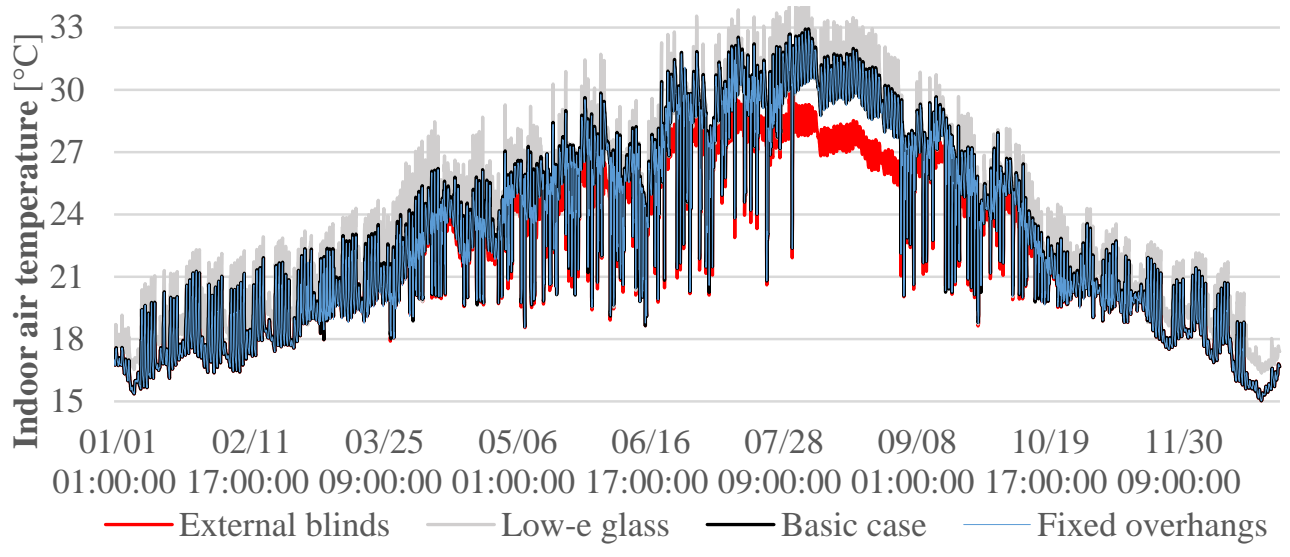

Figure 10. Indoor zone air temperature of the office zone in free running conditions.

Regarding the investigation of the office module, as in the previous analysis, the combined case showed a higher share of energy savings on the cooling side, with a reduction of $13.78 \%$ of energy demand, and zero effect on heating for the single office module. Replacing half of the wall-wide window with a Trombe wall drastically reduced the heating demand, more than half of the required energy in the basic case and cut off one third of the cooling demand. Figure 11a shows the results of the simulations. The lighting load moved from $2.28 \mathrm{kWh} / \mathrm{m}^{2}$ in the full window configuration to just $2.65 \mathrm{kWh} / \mathrm{m}^{2}$ in the half-window one. The naturally ventilated indirect system reached a higher share of energy savings for building heating, around $62 \%$, but without a proper control system, its integration could be counterproductive: the cooling energy demand, indeed, rose from 3.21 to $3.91 \mathrm{kWh} / \mathrm{m}^{2}$. This last configuration highlights the possible impact of an integrated passive solar design on building energy consumption, as the combined use of direct and indirect system could generate a reduction of $50 \%$ of a common office building's energy demand: a higher share could be achieved taking into account ventilation, by exploiting the Trombe wall cavity as a solar chimney during the cooling season. Assuming the office module as a functional unit, we compared a 10-units building, as a benchmark of a small office facility, with the department building previously analyzed, which contains 32 office zones. Results in Figure 11b confirm the impact on cooling demand of the combined case, whereas neglectable energy savings in terms of heating demand have been achieved, thus implying that the reduction of heating load, around $15 \%$, achieved in the whole building analysis was mainly related to common spaces and wide laboratories. 


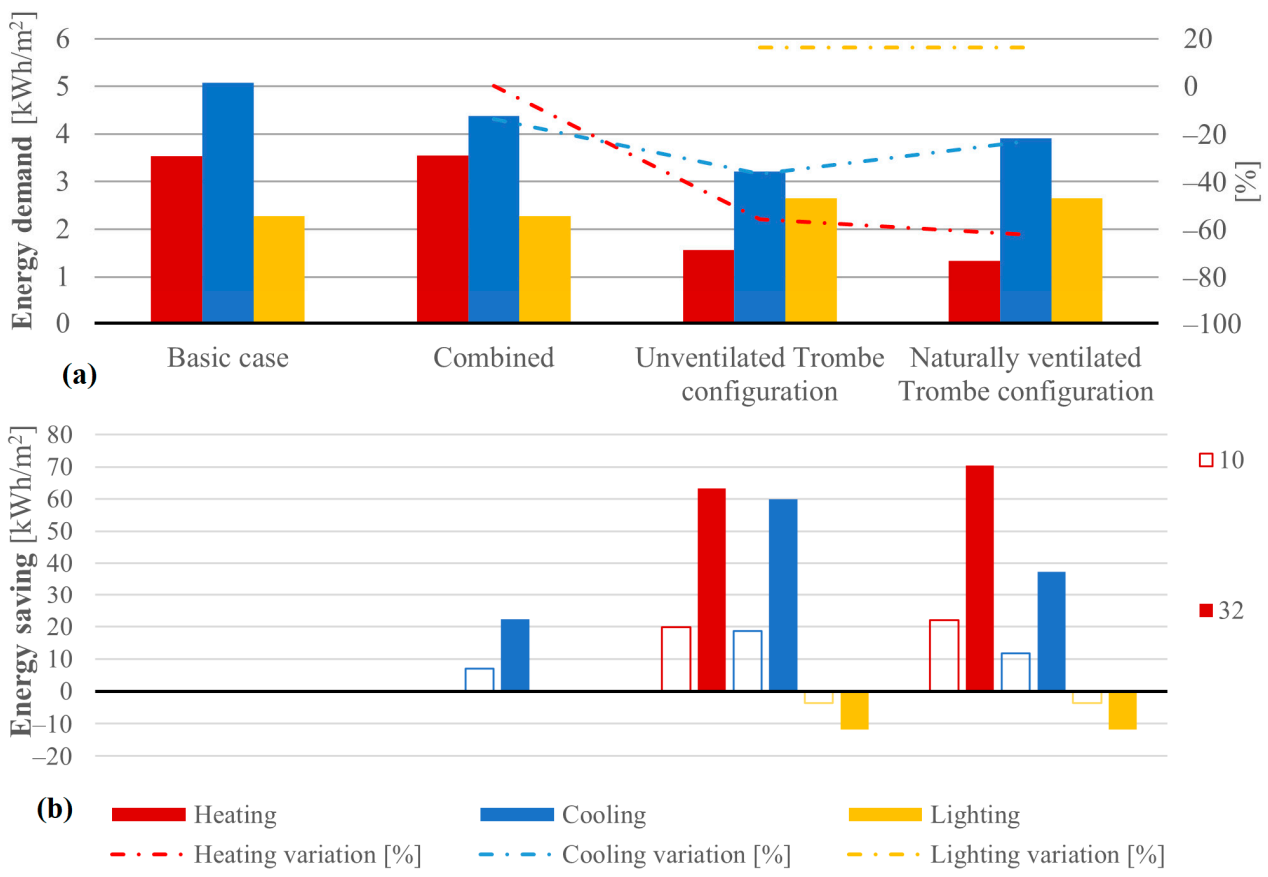

Figure 11. (a) energy demand of the office module and (b) energy saving of a 10- and 32-modules office building for different strategies.

The integration of the indirect system had a relevant impact on building energy saving: on heating demand, 65 to $70 \mathrm{kWh} / \mathrm{m}^{2}$ can be saved yearly in unventilated and ventilated configuration, respectively, for the department building. On the cooling side, the unventilated solution reached the highest saving, around $20 \mathrm{kWh} / \mathrm{m}^{2}$ for the small facility and $60 \mathrm{kWh} / \mathrm{m}^{2}$ for the larger structure: the lower values of ventilated strategies are related to the lack of monitoring systems to prevent ventilation of warmed air from the Trombe wall cavity to cause overheating.

\section{Discussion}

As exposed in the paper, the interest on the promotion of passive solar system solutions is relevant to reduce the energy impact of civil/residential structures. Other studies investigated the impact of specific variables: Djordjević et al. [31] developed a mathematical model to estimate the indoor temperature trend in a building with a combined passive solar system made of a direct and an unventilated Trombe wall. Their results show that an $80^{\circ}$ rotation of the room with a combined indirect passive system installed leads to indoor air temperatures about $40 \%$ lower than the temperatures in the south-oriented room. Results of Pathirana et al. [32] on shape factor influence indicate that the rectangular shape provides the higher thermal comfort, while window-to wall-ratio influence on thermal comfort is around $20-55 \%$. Investigations on specific passive solar solutions report results close to the ones showed in this paper. As showed by Owrak et al. [15] the installation of a sunspace can lead to a 10-15\% energy saving with no optimization: if a storage tank is added, the reduction can reach from at least $37 \%$ up to $87 \%$. Other optimized studies show energy saving percentage even higher than the present paper's data: the integration of a south-faced sunporch in China led to a coal saving rate of 51.9\% [33], while a Trombe wallrelated saving on a residential building in Portugal was about 43\% [20]. The difference in this case could both be due to the very low energy demand of the building, $14.95 \mathrm{kWh} / \mathrm{m}^{2}$, and the lower indoor comfort temperature setpoint, $18{ }^{\circ} \mathrm{C}$. Nevertheless, one of the major limits of the investigations on passive solar systems is the generalization of the results. Comparison of performance and savings from different research must take into account the boundary conditions of the passive strategies, such as latitude or kinds of building, which can hugely vary the impact on the total building energy demand. Due to the high 
number of variables defining the interaction of a building and a passive solar system, results from a specific case study or measurement from experimental activity cannot be generalized without proper assumptions. In addition, differently from common building systems, passive solutions deal with the building design at an architectural level to reach the high integration required, thus the sizing process and the optimization strategy of each solution must be tailored to the specific building. Thus, the main purpose of passive solar investigation should be to develop a general framework and guidelines for building design, or a protocol for the optimization process, as tools that can be adapted to different cases.

The sizing and design of a passive solar solution is not always simple. Moreover, the efficiency is related to multiple interconnected parameters, both on a technical and a climatic side, thus the evaluation and optimization of passive solar strategies needs to be carried out taking into accounts the different contribution of these factors to various elements: the energy balance, the cost of construction and maintenance, and the environmental impact. Another limit of passive solar analysis is proper technical and economic evaluation, usually based on a pure energy performance evaluation. As the synergy of intrinsic and extrinsic parameters defines the performance of passive solar solution, and the synergy of different systems can guarantee higher levels of energy savings as showed in the previous analysis, a synergy of evaluating factors determine the cost-benefit correlation to optimize this combination. Another element that can be considered in the analysis is the economic impact of the passive solar system, which is sometimes highly relevant. In general, the evaluation of the performance of a passive solar system can be carried out with different methods: an analysis exclusively based on energy balance or a life cycle analysis taking into account the environmental impact, with the related reduction of fuel consumption and greenhouses emissions, or economic analysis, to consider the payback time and the credit of original constructions elements replaced. A system design depends on the balance between the saving from energy consumption and the construction cost, during the lifespan. In these cases, as all the kinds of energy are equaled, the low available power and conversion efficiencies disadvantage the value of solar energy. In addition, this analysis is strictly country-dependent, as in some countries, the low price of energy, subsidized by the local government, results in even lower passive systems profitability [34]: in this perspective, the construction of passive solar systems strictly depends on the opportunity to exploit possible local benefits. As a result, a common economic analysis would not suggest the implementation of passive solar systems: to encourage the diffusion of this kind of strategies, the contribution to the reduction of greenhouse gas emissions or the energy degradation connected with the use of fossil fuels must constitute integral elements of the analysis. Possible alternatives may consist of two different approaches. A penalizing coefficient related to energy degradation could be introduced in the balance equation to promote the use of solar energy as a direct source: by counterbalancing the economic advantage of common energy vectors, this coefficient should enhance the use of natural energy. Otherwise, the evaluation must be based on a wider perspective through a multicriteria analysis that consider both technical, architectural, and energy stream-related issues.

\section{Conclusions}

Passive solar systems hide a huge potential as energy saving measures for buildings. The integration of different cooperating solutions in buildings is a relevant asset towards a nearly zero-energy building perspective. The design process is ruled by the synergy of various parameters, both intrinsic and extrinsic, that affect the performance and integrability of the passive solar system. In the paper, the authors have tried to define a general model for the definition of the performance of a passive solar system. The model is based on the combined consideration of direct and indirect thermal resistance and capacitive elements: it takes into account the massive capacitance of passive solar strategies in buildings and solar radiation variable resistances due to shading systems in summer and surrounding condition in winter, affecting the exploitation of diffuse and reflected solar radiation. As analyzed in the paper: 
- $\quad$ passive solar systems' standard design depends both on intrinsic parameters such as latitude and orientation that influence the effectiveness of the solution, and on the correlation of extrinsic factors like building structure and destination, which affect their integration, heat storage, and cost, all operating in a synergistic way;

- $\quad$ as a result of the general analysis, direct systems showed the highest energy saving percentage for offices, $28.2 \%$ and $38.5 \%$ for Rome and Frankfurt, respectively, in the rotated configuration, while the indirect solution performed better in residential application, with the Trombe wall rotated setting that reached a saving of $12.8 \%$ in Frankfurt and $22.3 \%$ in Rome;

- building use also influenced the latitude impact on energy savings: while in offices the saving increased with the latitude, the opposite occurred in residential buildings. Direct systems showed higher sensitivity to latitude, around 10\% variation of the energy saving, compared to the 2-6 percentage points in other cases, except for the indirect system in a residential building;

- the sensitivity to orientation variation decreased with increasing latitude, but generally south-oriented systems performed better than east-west ones: direct and indirect systems showed a higher range of variation, respectively, in Frankfurt for the office, $7.7 \%$, and in Rome for the residential application, $12.8 \%$;

- $\quad$ specific passive solar solutions on an existing public office building did not exceed $12 \%$, while the synergy of different solutions showed a reduction of energy consumption of almost $20 \%$. The application of synergistic passive solar systems can enhance the performance, saving more than $50 \%$ of the heating energy demand and up to $36 \%$ of the cooling load.

The integration of passive solar systems is hampered by performance evaluation: a simple energy balance disadvantages solar energy, characterized by low available power and low conversion efficiencies, while in an economic analysis, low energy costs, subsidized by some local government, makes them less cost-effective. Due to higher reliability and easier design, the integration of active devices has become a more common practice in the building market. In a long-term time frame, considering energy and carbon payback times, solar energy-based interventions, even for energy retrofit, proved to be profitable [7]. Future activity will continue both quantifying the impact of influencing parameters on passive solar system performance to develop a general framework useful to building design, analyzing combined solar systems. Research will focus on a proper way to evaluate the benefits of a passive solar design accounting on energy evaluation and energy degradation, by developing a multicriteria optimization function that considers each contribution of passive solar strategies.

Author Contributions: Conceptualization, A.F. and F.F.; methodology, A.F.; software, G.C.; writingoriginal draft preparation, G.C.; writing-review and editing, A.F. and F.F.; visualization and supervision, A.F. and F.F. All authors have read and agreed to the published version of the manuscript.

Funding: This research received no external funding.

Institutional Review Board Statement: Not applicable.

Informed Consent Statement: Not applicable.

Data Availability Statement: The data presented in this study are available in article.

Conflicts of Interest: The authors declare no conflict of interests. 


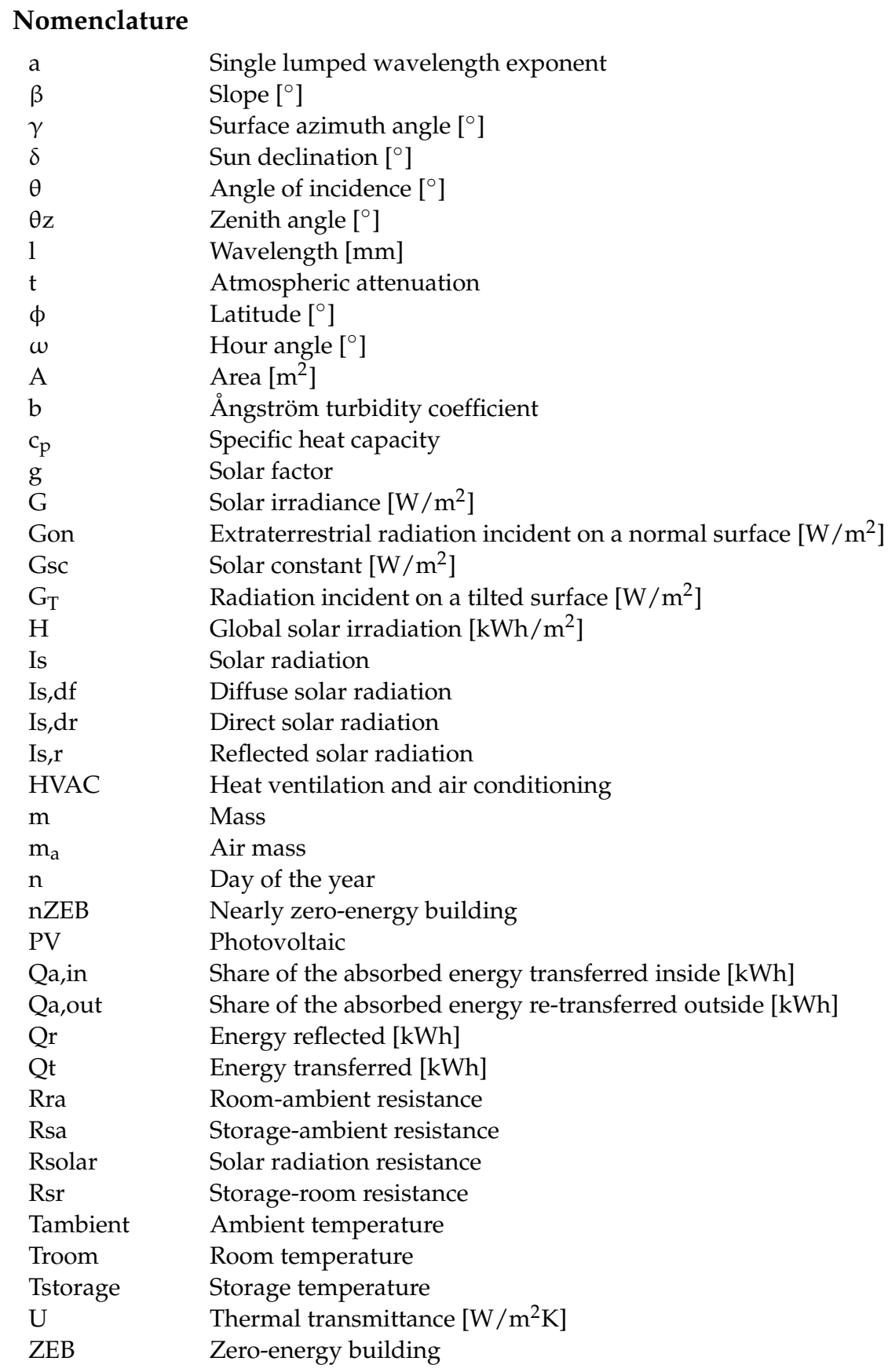

\section{References}

1. IEA. World Energy Balances and Statistics. Available online: https://www.iea.org/subscribe-to-data-services/world-energybalances-and-statistics (accessed on 28 November 2020).

2. Serghides, D.K.; Georgakis, C.G. The building envelope of Mediterranean houses: Optimization of mass and insulation. J. Build. Phys. 2012, 36, 83-98. [CrossRef]

3. Oldewurtel, F.; Parisio, A.; Jones, C.N.; Gyalistras, D.; Gwerder, M.; Stauch, V.; Lehmann, B.; Morari, M. Use of model predictive control and weather forecasts for energy efficient building climate control. Energy Build. 2012, 45, 15-27. [CrossRef]

4. IEA. Tracking Buildings 2019; IEA: Paris, France, 2019.

5. REN21. Renewables 2019 Global Status Report; REN21: Paris, France, 2019.

6. IEA (International Energy Agency). Tracking Buildings 2020; IEA: Paris, France, 2020.

7. Tsalikis, G.; Martinopoulos, G. Solar energy systems potential for nearly net zero energy residential buildings. Sol. Energy 2015, 115, 743-756. [CrossRef]

8. Franco, A.; Fantozzi, F. Experimental analysis of a self-consumption strategy for residential building: The integration of PV system and geothermal heat pump. Renew. Energy 2016, 86, 1075-1085. [CrossRef] 
9. Fantozzi, F.; Filipeschi, S.; Mameli, M.; Nesi, S.; Cillari, G.; Mantelli, M.B.H.; Milanez, F.H. An Innovative Enhanced Wall to Reduce the Energy Demand in Buildings. J. Phys. Conf. Ser. 2017, 796, 012043. [CrossRef]

10. Balcomb, J.D.; Barley, D.; McFarland, R.; Perry, J., Jr.; Wray, W.; Noll, S. Passive Solar Design Handbook—Volume Two of Two: Passive Solar Design Analysis; U.S. Department of Energy: Washington, DC, USA, 1980.

11. Cillari, G.; Fantozzi, F.; Franco, A. Passive solar systems for buildings: Performance indicators analysis and guidelines for the design. E3S Web Conf. 2020, 197, 02008. [CrossRef]

12. Givoni, B. Building Design Guidelines for Solar Energy Technologies. Master's Thesis, University of California, Los Angles, CA, USA, 1989.

13. Olgyay, V. Bioclimatic orientation method for buildings. Int. J. Biometeorol. 1967, 11, 163-174. [CrossRef]

14. Bevilacqua, P.; Benevento, F.; Bruno, R.; Arcuri, N. Are Trombe walls suitable passive systems for the reduction of the yearly building energy requirements? Energy 2019, 185, 554-566. [CrossRef]

15. Owrak, M.; Aminy, M.; Jamal-Abad, M.T.; Dehghan, M. Experiments and simulations on the thermal performance of a sunspace attached to a room including heat-storing porous bed and water tanks. Build. Environ. 2015, 92, 142-151. [CrossRef]

16. Balcomb, J.D.; Barley, D.; McFarland, R.; Perry, J., Jr.; Wray, W.; Noll, S. Passive Solar Design Handbook-Volume One of Two: Passive Solar Design Concepts; U.S. Department of Energy: Washington, DC, USA, 1980.

17. Huang, Y.; Niu, J.; Chung, T. Comprehensive analysis on thermal and daylighting performance of glazing and shading designs on office building envelope in cooling-dominant climates. Appl. Energy 2014, 134, 215-228. [CrossRef]

18. Alhuwayil, W.K.; Abdul Mujeebu, M.; Algarny, A.M.M. Impact of external shading strategy on energy performance of multi-story hotel building in hot-humid climate. Energy 2019, 169, 1166-1174. [CrossRef]

19. Nielsen, T.R.; Duer, K.; Svendsen, S. Energy performance of glazings and windows. Sol. Energy 2001, 69, 137-143. [CrossRef]

20. Lohmann, V.; Santos, P. Trombe Wall Thermal Behavior and Energy Efficiency of a Light Steel Frame Compartment: Experimental and Numerical Assessments. Energies 2020, 13, 2744. [CrossRef]

21. Wang, W.; Tian, Z.; Ding, Y. Investigation on the influencing factors of energy consumption and thermal comfort for a passive solar house with water thermal storage wall. Energy Build. 2013, 64, 218-223. [CrossRef]

22. Krüger, E.; Fernandes, L.; Lange, S. Thermal performance of different configurations of a roof pond-based system for subtropical conditions. Build. Environ. 2016, 107, 90-98. [CrossRef]

23. Imessad, K.; Derradji, L.; Messaoudene, N.A.; Mokhtari, F.; Chenak, A.; Kharchi, R. Impact of passive cooling techniques on energy demand for residential buildings in a Mediterranean climate. Renew. Energy 2014, 71, 589-597. [CrossRef]

24. Suárez López, M.J.; Castro, S.S.; Manso, A.N.; Marigorta, E.B. Heat collection in an attached sunspace. Renew. Energy 2020, 145, 2144-2150. [CrossRef]

25. Allesina, G.; Ferrari, C.; Muscio, A.; Pedrazzi, S. Easy to implement ventilated sunspace for energy retrofit of condominium buildings with balconies. Renew. Energy 2019, 141, 541-548. [CrossRef]

26. Mokrzecka, M. Influence of building shape and orientation on heating demand: Simulations for student dormitories in temperate climate conditions. E3S Web Conf. 2018, 44, 00117. [CrossRef]

27. Duffie, J.A.; Beckman, W.A. Solar Engineering of Thermal Processes, 4th ed.; John Wiley \& Sons Inc.: Hoboken, NJ, USA, 2012; ISBN 978-0470873663.

28. Balcomb, J.D. Heat storage and distribution inside passive solar buildings. In Proceedings of the 2nd International PLEA Conference on Passive and Low Energy Architecture, Crete, Greece, 28 June-1 July 1983.

29. Givoni, B. Characteristics, design implications, and applicability of passive solar heating systems for buildings. Sol. Energy 1991, 47, 425-435. [CrossRef]

30. EC. Directive 2010/31/EU of the European Parliament and of the Council on the Energy Performance of Buildings; European Commission: Belgium, Switzerland, 2010.

31. Djordjević, A.V.; Radosavljević, J.M.; Vukadinović, A.V.; Malenović Nikolić, J.R.; Bogdanović Protić, I.S. Estimation of Indoor Temperature for a Passive Solar Building with a Combined Passive Solar System. J. Energy Eng. 2017, 143, 04017008. [CrossRef]

32. Pathirana, S.; Rodrigo, A.; Halwatura, R. Effect of building shape, orientation, window to wall ratios and zones on energy efficiency and thermal comfort of naturally ventilated houses in tropical climate. Int. J. Energy Environ. Eng. 2019, 10, 107-120. [CrossRef]

33. Liu, Z.; Wu, D.; He, B.-J.; Wang, Q.; Yu, H.; Ma, W.; Jin, G. Evaluating potentials of passive solar heating renovation for the energy poverty alleviation of plateau areas in developing countries: A case study in rural Qinghai-Tibet Plateau, China. Sol. Energy 2019, 187, 95-107. [CrossRef]

34. Imessad, K.; Messaoudene, N.A.; Belhamel, M. Performances of the Barra-Costantini passive heating system under Algerian climate conditions. Renew. Energy 2004, 29, 357-367. [CrossRef] 